\title{
Abdominal and Gastrointestinal Infection
}

National Cancer Institute

\section{Source}

National Cancer Institute. Abdominal and Gastrointestinal Infection. NCI Thesaurus. Code C36070.

An infection that affects the gastrointestinal system and the abdomen. 